\title{
The complete nucleotide sequence of the gene encoding the nontoxic component of Clostridium botulinum type E progenitor toxin
}

\author{
Nobuhiro FujiI, ${ }^{1 *}$ Kouichi Kimura, ${ }^{1}$ Noriko Yokosawa, ${ }^{1}$ Teruo Yashiki, ${ }^{2}$ Kayo Tsuzuki ${ }^{1}$ \\ and KeIJI OGUMA ${ }^{1}$ \\ ${ }^{1}$ Department of Microbiology, Sapporo Medical College, S1, W17, Sapporo 060, Japan \\ ${ }^{2}$ Laboratory of Technology, College of Medical Technology, Hokkaido University, Sapporo 060, Japan
}

(Received 12 June 1992; revised 7 September 1992; accepted 14 September 1992)

\begin{abstract}
We have analysed the genes borne on a $6.0 \mathrm{~kb}$ HindIII fragment cloned from the chromosome of Clostridium botulinum type E strain Mashike. This fragment, cloned within plasmid pU9EMH, contains part of the structural gene for botulinum toxin type $\mathbf{E}$ neurotoxin as well as the entire structural gene for a nontoxic component of botulinum type $\mathrm{E}$ progenitor neurotoxin gene, ent-120. ent-120 is transcribed in the same direction as the neurotoxin gene and consists of one open reading frame encoding 1162 amino acid residues. Western blotting with anti-nontoxic component sera demonstrates that ent-120 encodes a protein of $120 \mathrm{kDa}$ which forms part of the nontoxic component. ent-120 is homologous to an analogous gene found in botulinum type $C$ strains $(69 \cdot 3 \%$ identity at the nucleotide level and $56.1 \%$ at the amino acid level). Two stretches of amino acids at the $\mathrm{N}$-terminus of the ent-120 protein are highly homologous to amino acid sequences within the type $\mathbf{E}$ neurotoxin. The stop codon of the ent-120 gene is situated 27 nucleotides upstream from the start codon of the neurotoxin gene.
\end{abstract}

\section{Introduction}

Botulinum toxins, produced by Clostridium botulinum, are extremely potent neurotoxins which inhibit the release of acetylcholine at the neuromuscular junction. They are classified into seven groups (A to $G$ ), based on the antigenicity of the toxin. The $7 \mathrm{~S}$ neurotoxin is synthesized as a single polypeptide chain of molecular mass $150 \mathrm{kDa}$, which undergoes cleavage to form a dichain molecule linked through a disulphide bond. The heavy chain $(100 \mathrm{kDa})$ correlates with the binding of toxin to peripheral synapses, and the light chain is associated with the intracellular activity of blocking acetylcholine release (Kimura et al., 1992). These toxins are produced as progenitor toxins of large molecular sizes: of 12S (M toxin), 16S (L toxin) and 19S (LL toxin) in culture supernatants. Three di erent molecular forms have been demonstrated in botulinum type A toxin (Sugii \& Sakaguchi, 1975).

$\mathrm{L}$ and $\mathrm{M}$ toxins are recognized in botulinum type $\mathrm{C}$ and D toxins (Ohishi \& Sakaguchi, 1980). Type E toxin

\footnotetext{
* Author for correspondence. Fax 116125861.

The nucleotide sequence data reported in this paper will appear in the DDBJ, EMBL and GenBank Nucleotide Sequence Databases with the accession number D12679.
}

is exclusively composed of $\mathbf{M}$ toxin (Kitamura et al., 1968). L and LL toxins show haemagglutinin activity, but $\mathbf{M}$ toxin does not (Ohishi \& Sakaguchi, 1980). Molecular dissociation of these progenitor toxins into toxic and nontoxic components occurs in alkaline conditions (Ohishi \& Sakaguchi, 1980). The nontoxic component of $\mathrm{L}$ or LL toxin is formed by conjugation of the nontoxic component of $\mathrm{M}$ toxin with the haemagglutinin. It has been suggested that the nontoxic components are necessary to maintain oral toxicity or to cause food poisoning because they prevent the $7 \mathrm{~S}$ neurotoxin from degradation by gastric juices at low $\mathrm{pH}$ (Ohishi et al., 1977; Ohishi \& Sakaguchi, 1980). The molecular composition of the nontoxic fractions is not clear, but they appear to contain haemagglutinin and other macromolecules.

We have previously cloned and determined the complete nucleotide sequences of the structural genes for the haemagglutinin subcomponent (HA-33) and a nontoxic-nonHA component (nontoxic component of $\mathrm{M}$ toxin) of $C$. botulinum type $C$ progenitor toxin (Tsuzuki et al., 1990, 1992). In other types of C. botulinum, the molecular constitution of the nontoxic component is less clear.

Type $\mathrm{E}$ progenitor toxin ( $\mathrm{M}$ toxin) consists of a nontoxic component and the neurotoxin (Kitamura et al., 1968). The nontoxic component contains no haem- 
agglutinin activity. In this paper, we describe the cloning of the gene encoding the nontoxic component of $\mathrm{M}$ toxin from chromosomal DNA of $C$. botulinum type $\mathrm{E}$ strain Mashike.

\section{Methods}

Recombinant plasmids for DNA sequencing and Western blotting analysis. The recombinant plasmid pU9EMH contains a $6.0 \mathrm{~kb} H$ HindIII fragment encoding the entire light chain and the $\mathrm{N}$-terminal portion of the heavy chain of botulinum type E neurotoxin (Fujii et al., 1992). pU9EMH DNA was digested with $X b a \mathrm{I}$ and $K p n \mathrm{I}$, then deleted by using a Takara deletion kit containing exonuclease III, Mungbean nuclease and Klenow enzyme (Takara Shuzo Co.). Escherichia coli MV 1184 cells transformed with the deleted pU9EMH were plated on TY agar plates $(0.8 \%, \mathrm{w} / \mathrm{v}$, tryptone, $0.5 \%$ yeast extract, $0.5 \% \mathrm{NaCl}$, $1.5 \%$ agar, $50 \mu \mathrm{g}$ ampicillin $\mathrm{ml}^{-1}$ ). Plasmids containing deletions were prepared by alkaline lysis of transformed E. coli MV 1184, and DNA fragments with appropriate sizes were selected by agarose gel electrophoresis.

Western blotting and DNA sequencing. Cultures of E. coli MV 1184 transformed with deletion mutants were grown in liquid medium and lysed by sonication; the protein products were separated by SDSPAGE, and Western blot analysis was carried out as described previously (Fujii et al., 1991, 1992; Tsuzuki et al., 1990). Anti-type E nontoxic component rabbit serum (7S-NT), which reacts with the nontoxic component of botulinum type E progenitor toxin (Yokosawa et al., 1986), but not with neurotoxin, and the monoclonal antibody (EL161-38) specific for type E neurotoxin were used in Western blot analyses. To reduce background, a 1:1000-diluted antiserum was treated with about $1 \mathrm{mg} \mathrm{ml}^{-1}$ of E. coli MV 1184 extracts for $30 \mathrm{~min}$ before adding to the filter.

The deletion mutants of pU9EMH described above were used to determine the DNA sequence of the nontoxic component gene of botulinum type E progenitor toxin. DNA sequences were determined by the dideoxy chain-termination method using $\left[\alpha-{ }^{35}\right.$ S $]$ dATP (NEN Products) and a T7 DNA sequencing kit (Pharmacia LKB Biotechnology), in accordance with the manufacturer's instructions (Fujii et al., 1990, 1991).

\section{Results}

\section{Western blotting analysis of gene products}

The proteins expressed from E. coli MV 1184 containing pU9EMH were analysed by SDS-PAGE and Western blotting. In addition to the $100 \mathrm{kDa}$ protein fragment of type E neurotoxin identified with monoclonal antibody EL161-38 (Fujii et al., 1992), pU9EMH also produced a protein band of approximately $120 \mathrm{kDa}$ which reacted with anti-7S-NT rabbit serum recognizing the nontoxic component of type E progenitor toxin (M toxin) (Fig. $1 a)$. The $120 \mathrm{kDa}$ protein did not react with monoclonal antibody EL161-38 recognizing type E neurotoxin. The gene encoding the $120 \mathrm{kDa}$ protein was designated as ent-120.

A series of plasmids containing various deletions of the $6.0 \mathrm{~kb}$ DNA fragment was prepared. The gene products from these deletion mutants were analysed by
Western blotting using 7S-NT serum. Three plasmids containing a DNA fragment larger than $3.7 \mathrm{~kb}$ (pU9EHD16, pU9EH-D0 and pU9EMH) produced the $120 \mathrm{kDa}$ protein. Lower molecular mass proteins were produced by plasmids containing inserts smaller than $3.7 \mathrm{~kb}$ (pU9EH-D23, pU9EH-D29 and pU9EH-D12) (Fig. $1 b$ ). These results suggested that the entire ent- 120 gene was located within the $3.7 \mathrm{~kb}$ fragment contained in pU9EHD16. Furthermore, deletion of about $500 \mathrm{bp}$ from the $5^{\prime}$-terminus of the $6.0 \mathrm{~kb}$ fragment (pU9EH-RD1) resulted in no expression of the $120 \mathrm{kDa}$ protein, suggesting that in this construct the promoter region has been deleted. Therefore, we concluded that the genes for ent120 and type E neurotoxin were probably transcribed in the same direction (Fig. $1 b$ ). In contrast to the plasmids containing deletions of the toxin gene, pU9EH-RDI still produced the $100 \mathrm{kDa}$ toxin polypeptide. Thus although the putative promoter for ent-120 has been deleted, the promoter region necessary for the expression of the $100 \mathrm{kDa}$ toxin gene in $E$. coli is still present.

\section{Nucleotide and deduced amino acid sequences of ent-120 gene}

The complete DNA sequence of the ent-120 gene was determined and is shown in Fig. 2. One open reading frame was composed of 1162 amino acid residues (3486 nucleotides), initiating at nucleotide position 163 with an ATG codon and terminating at position 3649 with a TAA stop codon. The molecular mass calculated from the deduced amino acid sequence was $136849 \cdot 3 \mathrm{Da}$, a value slightly higher than that estimated from the blotting analysis described above. The $\mathrm{N}$-terminal amino acid sequence of the ent-120 gene was very similar (22 out of 30 amino acid residues identical) to that of the botulinum type $\mathrm{E}$ nontoxic component reported by Somers \& DasGupta (1991). The amino acid residues which differ are marked with stars in Fig. 2. The high degree of identity between the amino acid sequence of the nontoxic component and the deduced sequence of ent-120 strongly suggests that ent-120 encodes the nontoxic component of botulinum type $\mathrm{E}$ progenitor toxin.

In the 5 -untranslated region of the ent-120 gene, sequences homologous to the Shine-Dalgarno and to the -10 regions of typical E. coli promoters were found $16 \mathrm{bp}$ and $107 \mathrm{bp}$ upstream from the translation initiation start codon respectively (Fig. 2). There was no similarity in the promoter region between the botulinum type $\mathrm{E}$ and type $\mathrm{C}$ nontoxic component genes. However, sequences resembling the promoters of the $C$. botulinum type $\mathrm{A}$ and Clostridium tetani neurotoxin genes were detectable in those regions of both the type $\mathrm{E}$ and type $\mathrm{C}$ nontoxic component genes (Fig. 2). These sequences may 


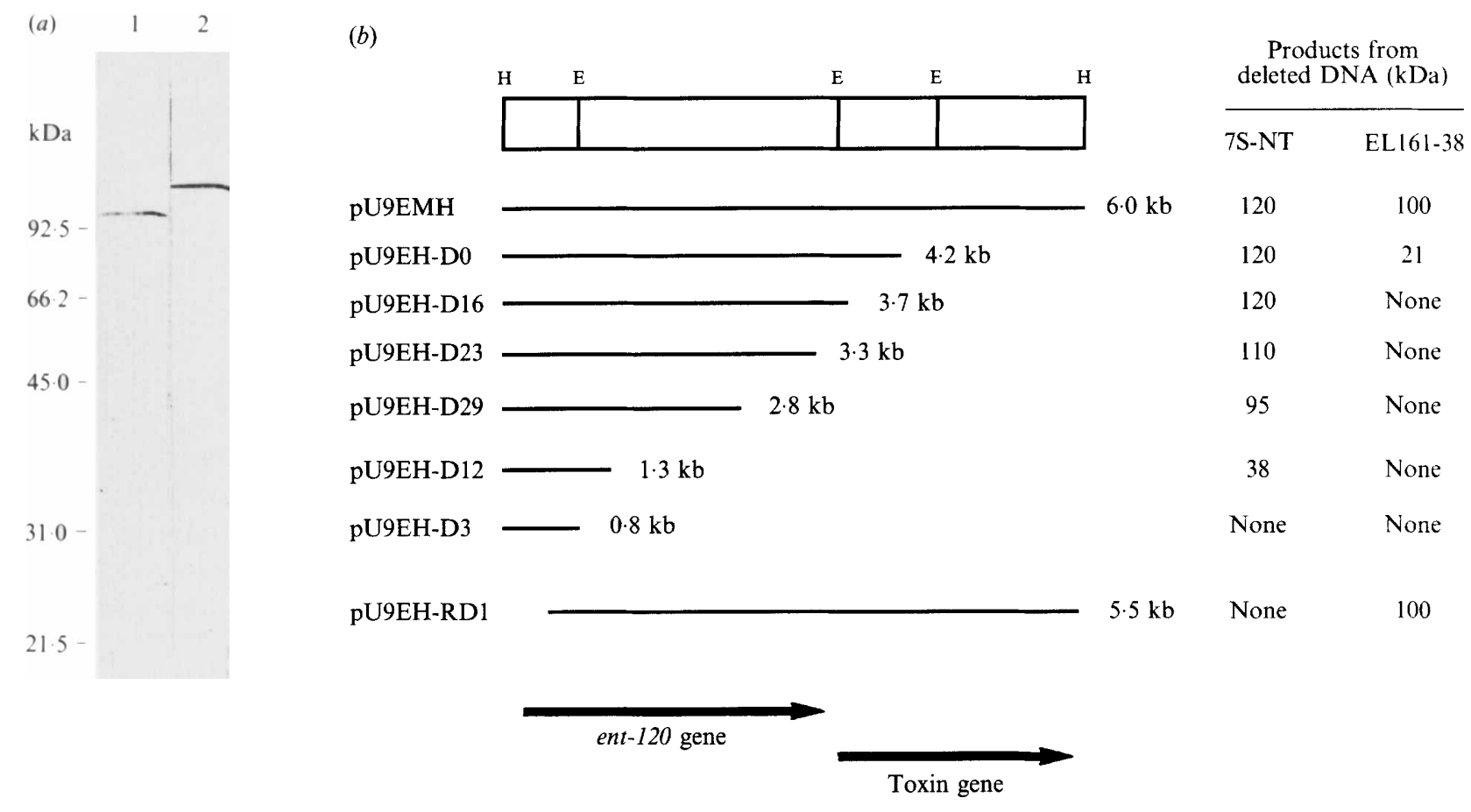

Fig. 1. Characterization of proteins produced by recombinant plasmids. (a) Extracts of E. coli MV 1184 transformed with pU9EMH were analysed by Western blotting with anti-neurotoxin monoclonal antibody (EL161-38) (lane 1) and anti-nontoxic component antiserum (7S-NT) (lane 2). (b) The recombinant plasmid pU9EMH was deleted with exonuclease III and transformed into E. coli MV 1184, and then gene products were analysed by Western blotting with monoclonal antibody EL161-38 and antiserum 7S-NT. The arrows indicate the orientations of the nontoxic component (ent-120) and neurotoxin genes. E, Eco RI; H, HindIII.

act as promoters in C. botulinum strains. Furthermore, the -35 region (TTTACA) of the lactose operon gene was also found near the putative -35 regions of both nontoxic component genes (indicated with a box in Fig. 2). Surprisingly, as shown in Fig. 2 , the $C$. botulinum ent120 gene was separated from the type E neurotoxin gene by only 27 nucleotides, although no promoter-like sequence was found in this region. A similar result was found with the type $\mathrm{C}$ neurotoxin and nontoxic component genes (Tsuzuki et al., 1992).

Comparative studies on amino acid sequences between botulinum type $E$ and type $C$ nontoxic component

Sequence comparison of type $\mathrm{E}$ and type $\mathrm{C}$ nontoxic components reveals approximately $69.3 \%$ identity at the nucleotide level and $56.1 \%$ at the amino acid level. Amino acid sequences homologous of those of type $\mathrm{C}$ are underlined in Fig. 2. This is an interesting result in the light of the low homology at the amino acid level between the neurotoxins of $C$. botulinum types $\mathrm{E}$ and $\mathrm{C}$ (Poulet et al., 1992; Whelan et al., 1992b). This suggests that the nontoxic components are composed of highly conserved amino acid sequences, in contrast to the botulinum neurotoxins. The two nontoxic components have similar hydrophobicity patterns (data not shown). We reported previously that the $\mathrm{N}$-terminal amino acid sequences of the type $\mathrm{C}$ nontoxic component and type $\mathrm{C}$ neurotoxin showed high homology (Tsuzuki et al., 1992). Similar homology in the N-terminal amino acid sequences is also found between the type $\mathrm{E}$ nontoxic component and botulinum toxins types A, B, C, D and E, and tetanus neurotoxins (Fig. 3). Nevertheless, there is no immunological cross-reaction between type $\mathrm{E}$ nontoxic component and other neurotoxins (data not shown).

\section{Discussion}

Type E botulinum neurotoxin is produced as a progenitor toxin ( $M$ toxin) in culture supernatants (Kitamura et al., 1968). The progenitor toxin dissociates into the neurotoxin and the nontoxic component in alkaline conditions (Kitamura et al., 1968; Sugii \& Sakaguchi, 1975). In this paper, we report the nucleotide sequence of the structural gene for the type E nontoxic component, and the possibility of polycistronic transcription of the botulinum type E nontoxic component and neurotoxin genes. The botulinum type $\mathrm{E}$ nontoxic component gene has one open reading frame ( 3486 nucleotides) coding for 
1 AAG CTT TCG TGA TTC CTT AGC TTT IGA ATT AGC AAA TAA TIT TAC AJA $-35$ t9 TAT AAT AAA TOA TAT TGT AAA TTG GAA TAA TTT AAA AAT TTC AGA GGT

97 TAC AAA TAT TAT TTT AAA TGT TGG ATT TTG TAT ACA GGA AAT ATG AAT TAA AGA GGG TOA AAA TTT SD ATG AAA ATA AAT GGT AAT TTA AAT ATT GAT Met Lys Ile Asn Gly Asn LeU Asn lle Asp

193 TCT CCT GTA GAT AAT AAG AAT GTA OCA ATT GTT AGA AGT AGA AAT CAG

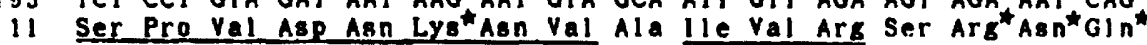

241 ATG TTT TTT AAA GCA TTT CAA GTG GCT CCC AAT ATA TGG ATA GTC CCA Met Phe Phe Ly Ala Phe GIn val ala Pro asn Ile Trp lle Val Pro

289 GAA AGA TAT TAT GGA GAA TCA TTA AAG ATA AAT GAA GAT CAA AAA TTT

13 Glu Ars Tyr Tyr Gly Glu Ser Leu Lys Ile Asn Glu Asp Gln Lys Phe

337

59

385

75

433

91

481 GAT GGT GGA ATT TAT GAT TCT AAT TTT CTT TCA ACA AAT AAT GAA AAG Asp GIY GIy lle Tyr Asp Ser Asn Phe Leu Ser Thr Asn Asn Glu Lys

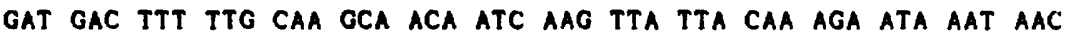
Asp Asp Phe Leu Gin Ala Thr lle lys leu Leu Gin arg lle asn asn AAT GTT GTA GGT GCA AAG TTA TTA TCT TTA ATT TCT ACA GCT ATT CCT Asn Val Val Gly Ala lys Lell Leu Ser Leu lle Ser Thr Ala lle Pro TTT CCT TAT GAA AAT AAT ACT GAA GAT TAT AGA CAG ACT AAC TAC CTT Phe Pro Tyr Glu Asn Asn Thr Glu Asp Tyr Arg Gln Thr Asn Tyr Leu AGT TCT AAG AAT AAT GAA CAT TAT TAT ACA GCT AAC TTA GTT ATT TTT Ser Ser Lys Asn Asn Glu His Tyr Tyr Thr Ala Asn Leu Val lle Phe GGA CCA GGA TCA AAT ATA ATA AAA AAT AAT GTT ATT TAT TAT AAA AAA Gly Pro Gly Ser Asn lle Ile Lys Asn Asn Val Ile Tyr Tyr Lys Lys

GAA TAT GCA GAA aGT GGA ATG GGa aCC ATG TTA GAA aTA TGG TTT CAA Glu Tyr Ala Glu Ser Gly Met Gly Thr Met Leu Glu lle Trp Phe Gin CCA TTT TTA ACA CAT AAA TAT GAT GAA TTC TAT GTT GAT CCA GCT TTA Pro Phe Leu Thr his Lys Tyr Asp Glu Phe Tyr Val Asp Pro Ala Leu GAG TTA ATA AAA TGT TTA ATA AAA TCT CTT TAT TAT TTA TAT GGA ATA Glu leu lle Lys Cys Leu lle Lys Ser Leu Tyr Tyr Leu Tyr Giy lie

AAA CCT AAT GAT AAT TTA AAT ATT CCA TAT AGA TTA AGA AAT GAG TTT Lys Pro Asn Asp Asn Leu Asn lie Pro Tyr Arg l.eu Arg Asn Glu Phe AAT AGT TTA GAA TAT TCA GAG TTA AAT ATG ATT GAT TTT TTA ATA TCA Asn Ser Leu Glu tyr Ser Glu Leu Asn Met lle asp phe leu lle Ser GGA GGA ATT GAT TAT AAA CTT TTA AAT ACT AAT CCT TAT TGG TTT ATA Gly Gly lle Asp Tyr Lys leU LeU Asn Thr ABn Pro Tyr Trp Phe lle

GAT AAG TAT TTT ATT GAT ACT TCG AAA AAT TTT GAA AAA TAT AAA AAT Asp Lys Tyr Phe lle Aap Thr Ser Lys Asn Phe Glu Lys tyr Lys Asn

GAT TAT GAA ATA AAA ATT AAA AAT AAT AAT TAT ATT GCT AAT AGT ATT Asp Tyr Giu Ile lys lle lys asn asn abn tyr lle Ala asn Ser Ile

AAA TTA TAT TTA GAA CAA AAG TTT AAG ATT AAT GTA AAA GAT ATA TGG Lys Leu Tyr LeUl Glu gin Lys Phe Lys lie Asn Val Lys Asp lle Trp

GAA TTA AAT TTA AGT TAT TTT TCT AAA GAA TTT CAA ATC ATG ATG CCA Glu leu asn Leu Ser tyr Phe Ser Lys Glu Phe Gin lic Met Mel Pro

GAA AGA TAC AAT AAT GCA CTT AAT CAT TAT TAC AGA AAA GAA TTT TAT GIII Arg Tyr Asn ABn Ala Leu Asn 1118 Tyr Tyi Arg Lys Glu Phe TyI

GTA ATA GAT TAT TTT AAA AAT TAC AAT ATA AAT GGT TTT AAA AAT GGT Val Ile Asp Tyl Phe Lys Asn TyY Asn Ile Asn Gly Phe Lys Asn Gly

CAA ATt AAA aCA AAA TTA CCT TTA TCA AAA TAT AAC AAA OAG ATt aTA Gin lle Lys thr Lye Leu Pro Leu ser Lys Tyr Asn Lys Glu lie ile AAT AAG CCT GAA tTA ATA GTT AAC TTG ATA AAT CAA AAT AAT ACT GTA Asn Lye Proglu leu lie Val Aan Leu Jie Asn Gin ABn Asn Thr Val

TTG ATO AAA AGT AAT ATT TAT GGA GAT GGA TTA AAA GGG AAT GTG GAT Leu Met Lys ser Asn II Tyr Gly Asp Gly Leu Lys GIy Asn Val Asp

48

96

144

192

10

240

26

288

42

336

58

384

74

432

90

480

106

628

122

576

138

624

15.1

672

170

720

186

768

202

816

218

864

234

912

250

960

266

1008

282

1056

298

1104

311

1152 330

12011 $3+6$

Fig. 2. (For legend see page 84.) 
1315 AAT TTC TAT TCT AAT TAT ATA ATT CCC TAT AAT CTA AAT TAT GAA CAT 395 Asn Phe Tyr Ser ABn Tyr lle lle Pro Tyr Asn Leu ABn Tyr Glu his

1393 TCT ATT AAT TAT TTT TAT TTA GAT AAT GTA AAT ATC GAA GAA ATA GAA 111 Ser lle Asn Tyr Phe Tyr Leu Asp Asn Val Asn lle Glu Glu lle Glil

1441 AAA ATT CCT CCT ATT AAT GAT GAA GAT ATA TAT CCT TAT AGA AAA AAT 127 Lys lle Pro Pro Ile Asn Asp Glu ABp lle Tyr Pro Tyr Arg Lys Asn

1489 GCT GAT ACA TTT ATA CCA GTA TAT AAT ATT ACA AAA GCT AAG GAA ATT 143 Ala Asp Thr Phe lle Pro Val Tyr Asn Ile Thr Lys Ala Lys Glu IIe

1537 AAT ACT ACC ACA CCA TTA CCA GTA AAT TAT TTA CAG GCT CAA ATG ATA 159 Asn Thr Thr Thr Pro Leu Pro Val Asn Tyr Leu Gin Ala Gin Met Ile

1585 GAT AGT AAT GAT ATT AAC TTA TCC TCA GAT TTT CTA AAA GTA ATT TCT 475 Asp Ser Asn Asp lle Asn Leu Ser Ser Asp Phe Leu Lys Val lle Ser

IG33 TCT AAG GGA TCT TTA GTA TAT TCG TTT TTA AAT AAT ACA ATG GAT TAT 191 Ser Lys GIy ser Leu Val Tyr Ser Phe Leu Asn Asn Thr Mel Asp Tyr

1681 TTA GAG TTT ATA AAA TAC GAT AAA CCC ATT GAT ACA GAT AAA AAA TAT 507 Leu Glu Phe Ile Lys Tyr Asp Lys Pro lle Asp Thr Asp Lys Lys Tyr

1729 TAT AAG TGG TTA AAA GCA ATT TTT AGA AAT TAC TCT CTT GAT ATA ACA 523 Tyr Lys Typ Leu Lys Ala lle Phe Arg Asn Tyr Ser Leu Asp Ile Thr

1777 GAA ACT CAA GAA ATT AGT AAT CAA TTT GGA GAT ACT AAG ATA ATA CCA 539 Glu Thr Gln Glu lle Ser Asn Gln Phe Gly Asp Thr l.ys lle lle Pro

1825 TGG ATT GGT AGA GCA TTA AAT ATT CTA AAT ACA AAT AAT TCA TTT GTG 555 Trp lie Gly arg ala Leu Asn lle Leu Asn Thr Asn Asn Ser Phe Val

1873 GAG GAA TTT AAA AAC TTA GGA CCA ATT TCT CTT ATT AAT AAA AAA GAA jil Glu Glu Phe lys Asn Leu Gly Pro lie Ser beu lle Asn Lys Lys Giu

1921 AAT ATA ACT ATT CCT AAA ATA AAA ATT GAT GAA ATA CCT AGT AGT ATG E8T Asn lle Thr lle Pro Lys lle l.ys lle asp Glu lle Pro ser ser Mel

1969 TTG AAT TTT TCA TTT AAA GAT TTA AGT GAA AAT TTA ITT AAT ATA TAT 603 Leu Asn Phe Ser phe Lys Asp Leu ser Glu Asn Leu Phe Asn lle Tyr

2017 TGT AAA AAT AAT TTT TAT CTA AAA AAA ATT TAC TAT AAT TTT TTA GAT

619 Cys Lys Asn Asn Phe Tyr Leu Lys Lys 11 e Tyr Tyr Asn Phe Leu Asp

2065 CAA TGG TGG ACA CAA TAT TAT AGT CAA TAT TTT GAT CTA ATT TGT ATG 635 Gln Trp Trp Thr GIn Tyr Tyr Ser Gln Tyr Phe Asp Leu lle Cys Met

2113 GCT AGT AAA TCA GTA TTA GCT CAA GAA AAG TTA ATA AAA MAA CTA ATA

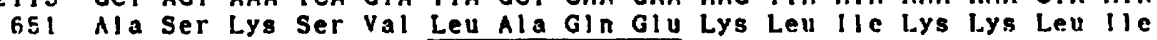

2161 CAA AAA CAA TTA AGG TAT TTA ATG GAA AAT TCT AAT ATA TCC TCT ACT $6 G 7$ GIn lys GIn Leu Arg Tyr Leu Mel GIU Asn Ser asn lie Ser Ser Thi

2209 AAT TTA ATA TTG ATA AAC TTA ACA ACC ACA AAT ACA TTA AGA GAT ATT 683 Asn Leu lle Leu lle Asn Leu Thr Thr Thr Asn Thr Leu Arg asp Ile

2257 TCA AAT CAA TCA CAA ATA GCA ATA AAT AAT ATA GAT AAA TTT TTT AAT 699 Ser asn Gin Ser gin lie ala lle Asn asn lle asp lys Phe Phe asn

2305 AAT GCT GCT ATG TGT GTT TTT GAA AAC AAT ATT TAT CCT AAA TTC ACT 715

2353 731

2.10 $7+7$

2.149

$2+97$

2503 Asn Ala Ala Met Cys Val Phe Glu Asn Asn lle Tyr Pro Lys Phe Thr

TCT TTT ATG GAA CAA TGT ATT AAA AAT ATA AAT AAA AGC ACC AAA GAG Ser Phe Met Glu GIn Cys lle Lys Asn. Ile Asn Lys Ser Thr Lys Glu Phe Ile LeU Lys Cys Thr Asn lle Asn Glu Thr glu Lys Ser His LeU

ATT ATG CAA AAT AGT TTT AGT AAT TTA GAT TTT GAT TTT TTA GAT ATT lle Mel Gin Asn ser Phe Ser Asn Leu Asp Phe asp Phe Leu Asp lle

CAa aAT atg aAg aAC CTA tTT aAT tTa tat aCa gaA CTa ctT ata aAa GIn Asn Met Lys Asn beu Phe Asn Leu Tyr Thr Glu Leu Leu lle Lys Glu Gin Thr ser Pro Tyr Glu Leu Ser Leu Tyr Ala Phe Gin Glu Gin

GAT AAC AAT GTT ATT GGA GAT ACA TCC GGT AAA AAT ACA TTA GTA GAA Asp Asn Asn Val lle Gly asp Thr Ser Gly Lys Asn Thr LeU Val Glu
TTT ATA CTA AAA TGT ACT AAT ATT AAT GAA ACT GAA AAA TCA CAC TTC
1392

410

1440

126

1488

$+42$

1636

458

1584

474

1632

490)

1680

$5(16$

1728

522

1776

538

1824

554

1872

570

1920 586

1968 602

2016 618

2064 634

2112 650

2160 666

2208 682

2256 698

2311) 714

2352

730

2400

$7+6$

$2+48$

762

$2+96$

778

$23+1$

794

2592

810

2640 826

Fig. 2 cont. (For legend see page 84.) 


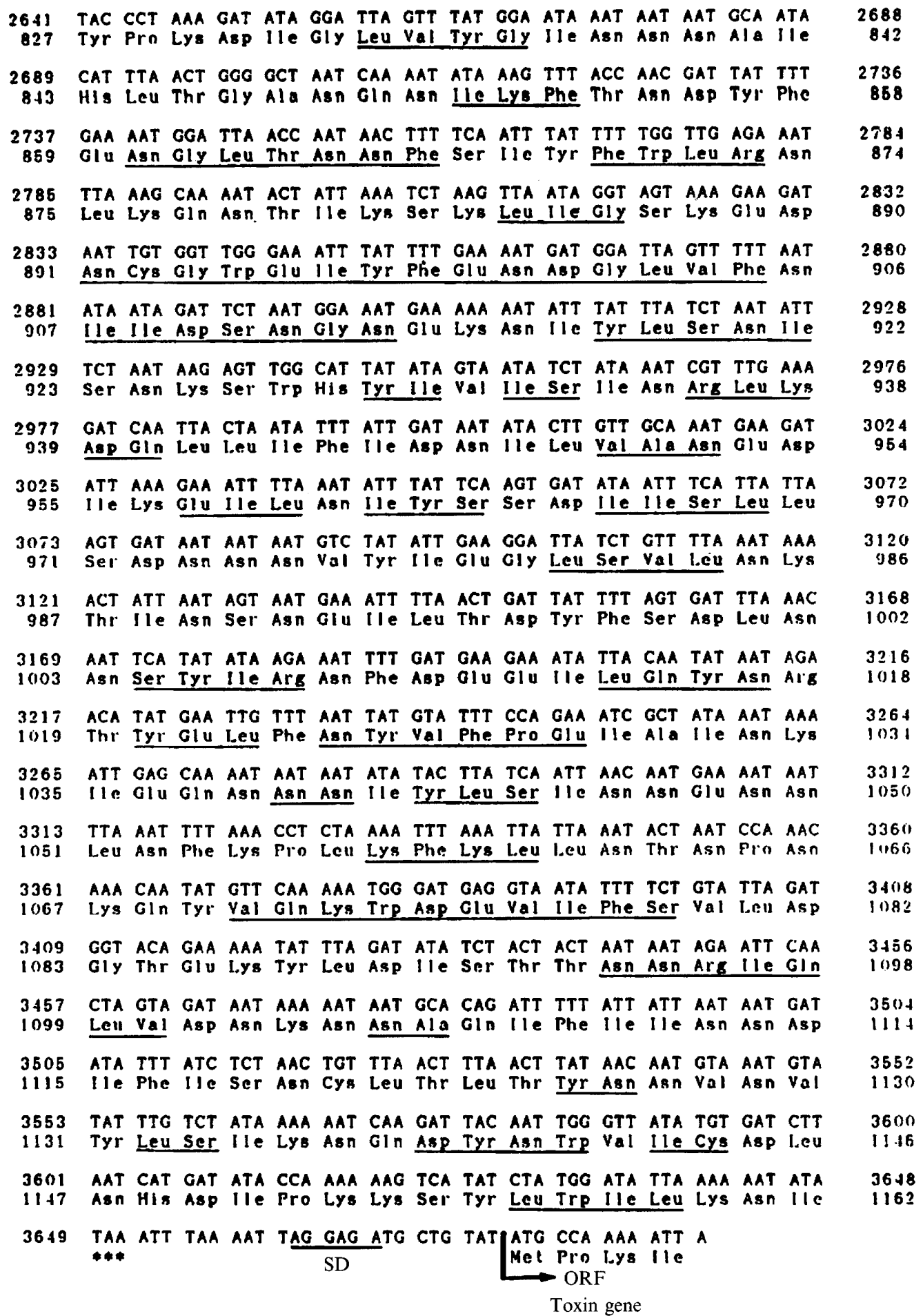

Fig. 2. Nucleotide and deduced amino acid sequences of botulinum type E nontoxic component gene. The putative Shine-Dalgarno sequence and the sequence homologous to -10 region of typical E. coli promoter are indicated by SD and TATA, respectively. The sequences identical to those of the botulinum type $\mathrm{C}$ nontoxic component (Tsuzuki et al., 1992) are underlined. The amino acid sequence of the $\mathrm{N}$-terminal region of type E nontoxic component reported by Somers \& DasGupta (1991) is indicated by double underlining. Other features marked on the sequence are discussed in the text. 
Progenitor toxin Position Amino acid sequence

Nontoxic component

Type E $\quad 30-44$

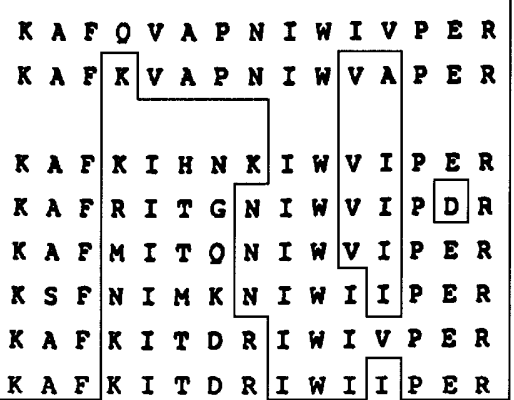

Nontoxic component

Type E $\quad 64-98$

Type C $\quad 65-99$

Neurotoxin

Type A $\quad 74-108$

Type C 73-107

Type D 73-107

Type E $\quad 70-104$

Tetanus 74-108

Type B 75-109

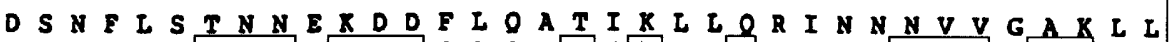
D S N F L S O D S E R E N F L O A I I I I L K R I N N T I S G K Q I L

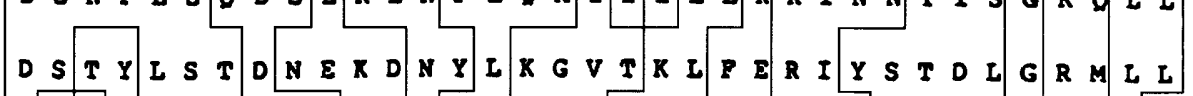

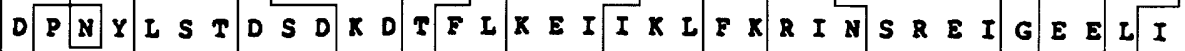

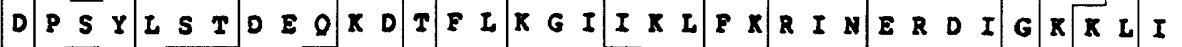
D P N Y L D F N T I I

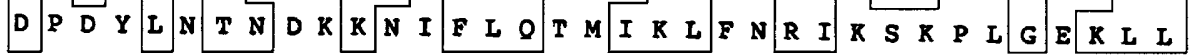

Nontoxic component Type E

102-113

Type C

$103-114$

S T A I P F P Y E N N T

Neurotoxin

Type C

$111-122$

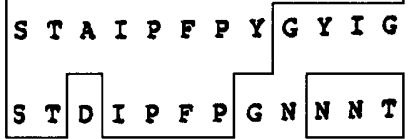

Fig. 3. Homology of deduced amino acid sequence among botulinum nontoxic components and neurotoxins. The sequence of type $\mathrm{E}$ nontoxic component is compared with those of botulinum type $\mathrm{C}$ nontoxic component (Tsuzuki et al., 1992), and botulinum type $\mathrm{A}$ (Binz et al., 1990a; Thompson et al., 1990), type B (Whelan et al., 1992a), type C (Kimura et al., 1990), type D (Binz et al., 1990 b), type E (Fujii et al., 1992; Poulet et al., 1992; Whelan et al., 1992b) and tetanus (Eisel et al., 1986; Fairweather \& Lyness, 1986) neurotoxins.

1162 amino acid residues. The type E nontoxic component is shorter than type $\mathrm{C}$ nontoxic component (1196 amino acid residues). Although the entire light chains of type $\mathrm{E}$ and type $\mathrm{C}$ neurotoxins are produced in $E$. coli MV 1184 cells harbouring recombinant plasmids of pU9EMH and pCL8, respectively (Kimura et al., 1990; Fujii et al., 1992), the mechanism of expression of the nontoxic component from these plasmids may be different. The type E nontoxic component is expressed in E. coli cells transformed with pU9EMH, but that of type C (pCL8) is never found (Tsuzuki et al., 1992). It is possible therefore that there are some differences in the activity of the promoter regions between type $\mathrm{E}$ and type $\mathrm{C}$ nontoxic component genes, as recognized by $E$. coli RNA polymerase. Comparative studies revealed that there is very little similarity in these promoter regions. It is still unclear which nucleotide sequences are essential for the expression of genes in C. botulinum. For the expression of type E progenitor toxin in E. coli cells, the neurotoxin and the nontoxic component are produced or transcribed independently because the recombinant plasmid pU9EH-RD1 (Fig. 1), which lacks 500 bp of the putative promoter region of ent-120, produces a $100 \mathrm{kDa}$ $\mathrm{N}$-terminal fragment of the type $\mathrm{E}$ neurotoxin. This is also confirmed by our previous finding that the $33 \mathrm{kDa}$ fragment of the type E neurotoxin is expressed from a

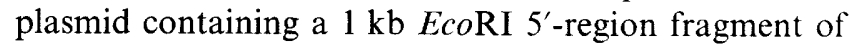
the type E neurotoxin gene (Fujii et al., 1990). A similar result is obtained from the plasmid containing a $2.8 \mathrm{~kb}$ HindIII $5^{\prime}$-region fragment $(1.9 \mathrm{~kb}$ of 5 -noncoding region and $0.9 \mathrm{~kb}$ of $5^{\prime}$-coding region) of the type $\mathrm{C}$ neurotoxin gene (unpublished data). However, it is clear that there is only $27 \mathrm{bp}$ between the stop codon of the type $\mathrm{E}$ nontoxic component gene and the start codon of the type E neurotoxin gene. Therefore, it is likely that some nucleotide sequence in the nontoxic component gene may work as a promoter for the neurotoxin gene in $E$. coli. Such a promoter region has been proposed by Fujii et al. (1990) and Whelan et al. (1992b): the '-10' region located between nucleotides 3535 and 3540 . However, such a sequence may not function as a promoter in C. botulinum. We suggest that the nontoxic 
component and neurotoxin genes are transcribed by a polycistronic mRNA species initiated from a promoter located in the 5'-untranslated region of the nontoxic component gene in $C$. botulinum. These results obtained from the nontoxic components of types $\mathrm{E}$ and $\mathrm{C}$ contrast with the work of Binz et al. (1990a), who showed that the transcription of botulinum type A neurotoxin initiates from just upstream of the start codon of the toxin gene. Thus the transcription system may vary in each type of C. botulinum. Primer extension and Northern blot experiments using mRNA from $C$. botulinum type $\mathrm{C}$ and $\mathrm{E}$ strains will be necessary to locate the transcriptional start sites and the size of mRNA from the neurotoxin and ent -120 genes.

Similarity between the type $\mathrm{E}$ and type $\mathrm{C}$ nontoxic components indicates that the nontoxic component may be highly conserved in C. botulinum, and it may play an important role. The $\mathrm{N}$-terminal regions of both the nontoxic component and neurotoxins of type $\mathrm{C}$ showed high homology (Tsuzuki et al., 1992). In the type $\mathrm{E}$ progenitor toxin, highly homologous regions are detectable between the nontoxic component and neurotoxin (Fig. 3). As the nontoxic component is closely associated with oral toxicity (Ohishi et al., 1977; Ohishi \& Sakaguchi, 1980), this component might act to protect neurotoxin from protease.

\section{References}

Binz, T., Kurazono, H., Wille, M., Frevert, J., Wernars, K. \& NiEmanN, H. $(1990 a)$. The complete sequence of botulinum neurotoxin $\mathrm{A}$ and comparison with other clostridial neurotoxins. Journal of Biological Chemistry 265, 9153-9158.

Binz, T., Kurazono, H., Popoff, M. R., Eklund, M. W., SaKaguchi, G., Kozaki, S., Krieglstein, K., Henschen, A., Gill, D. M. \& NiemanN, H. $(1990 \mathrm{~b})$. Nucleotide sequence of the gene encoding Clostridium botulinum neurotoxin D. Nucleic Acids Research 18, 5556.

Eisel, U., Jarausch, W., Goretzki, K., Henschen, A., Engels, J., Weller, U., Hudel, M., HakermanN, E. \& NiemanN, H. (1986). Tetanus toxin: primary structure, expression in E. coli, and homology with botulinum toxins. EMBO Journal 5, 2495-2502.

FAIR WEATHER, N. F. \& LYNESS, A. V. (1986). The complete nucleotide sequence of tetanus toxin. Nucleic Acids Research 14, 7809-7812.

FujiI, N., Kimura, K., Murakami, T., INDOH, T., Yashiki, T., Tsuzuki, K., Yokosawa, N. \& Oguma, K. (1990). The nucleotide and deduced amino acid sequences of $E c o$ RI fragment containing the 5 '-terminal region of Clostridium botulinum type E toxin gene cloned from Mashike, Iwanai and Otaru strains. Microbiology and Immunology 34, 1041-1047.

FujiI, N., Kimura, K., Yashiki, T., Indoh, T., Murakami, T., Tsuzuki, K., Yokosawa, N. \& Oguma, K. (1991). Cloning of a DNA fragment encoding the 5 -terminus of the botulinum type $\mathrm{E}$ toxin gene from Clostridium butyricum strain BL6340. Journal of General Microbiology 136, 519-525.

Fuji, N., Kimura, K., Yashiki, T., Tsuzuki, K., Morishi, K.,
Yokosawa, N., Syuto, B. \& Oguma, K. (1992). Cloning and whole nucleotide sequence of the gene for the light chain component of botulinum type E toxin for Clostridium butyricum strain BL6340 and Clostridium botulinum type E strain Mashike. Microbiology and Immunology 36, 213-220.

Kitamura, M., Sakaguchi, S. \& Sakaguchi, G. (1968). Purification and some properties of Clostridium botulinum type $\mathrm{E}$ toxin. Biochimica et Biophysica Acta 168, 207-217.

Kimura, K., Fuji, N., Tsuzuki, K., Murakami, T., Indoh, T., Yokosawa, N., Takeshi, K., Syuto, B. \& Oguma, K. (1990). The complete nucleotide sequence of the gene coding for botulinum $\mathrm{Cl}$ toxin in the c-st phage genome. Biochemical and Biophysical Research Communications 171, 1304-1311.

Kimura, K., Fuji, N., Tsuzuki, K., Yokosawa, N. \& Oguma, K. (1992). The functional domains of Clostridium botulinum type C neurotoxin. In Recent Advances in Toxinology Research, pp. 375-385. Edited by P. Gopalakrishnakone. Singapore: Venom and Toxin Research Group.

OHISHI, I. \& SaKaguchi, G. (1980). Oral toxicities of Clostridium botulinum type $\mathrm{C}$ and $\mathrm{D}$ toxins of different molecular sizes. Infection and Immunity 28, 303-309.

Ohishi, I., SugiI, S. \& Sakaguchi, G. (1977). Oral toxicities of Clostridium botulinum toxins in response to molecular size. Infection and Immunity 16, 107-109.

Poulet, S., Hauser, D., Quanz, M., Niemann, H. \& Popoff, M. R. (1992). Sequences of the botulinal neurotoxin $\mathrm{E}$ derived from Clostridium botulinum type E (strain Beluga) and Clostridium butyricum (strains ATCC 43181 and ATCC 43755). Biochemical and Biophysical Research Communications 183, 107-113.

SugII, S. \& SAKAGUCHI, G. (1975). Molecular construction of Clostridium botulinum type A toxins. Infection and Immunity 12. $1262-1270$

SOMERS, E. \& DasGupta, B. R. (1991). Clostridium botulinum types $\mathrm{A}, \mathrm{B}, \mathrm{C}$, and $\mathrm{E}$ produce proteins with or without hemagglutinating activity: do they share common amino acid sequences and genes? Journal of Protein Chemistry 10, 415-425.

Thompson, D. E., Brehm, J. K., Oultram, J. D., Swinfield, T. J., Shone, C. C., Atkinson, T., Melling, J. \& Minton, N. P. (1990). The complete amino acid sequence of the Clostridium botulinum type A neurotoxin, deduced by nucleotide sequence analysis of the encoding gene. European Journal of Biochemistry 189, 73-81.

Tsuzuki, K., Kimura, K., Fuji, N., Yokosawa, N., Indoh, T., Murakami, T. \& Oguma, K. (1990). Cloning and complete nucleotide sequence of the gene for the main component of hemagglutinin produced by Clostridium botulinum type C. Infection and Immunity 58, 3173-3177.

Tsuzuki, K., Kimura, K., Fuji, N., Yokosawa, N. \& Oguma, K. (1992). The complete nucleotide sequence of the gene coding for the nontoxic-nonhemagglutinin component of Clostridium botulinum type C progenitor toxin. Biochemical and Biophysical Research Communications 183, 1273-1279.

Whelan, S. M., Elmore, M. J., Bodsworth, N., Brehm, J. K., Atkinson, T. \& Minton, N. P. (1992a). Molecular cloning of the Clostridium botulinum structural gene encoding the type B neurotoxin and determination of its entire nucleotide sequence. Applied and Environmental Microbiology 58, 2345-2354.

Whelan, S. M., Elmore, M. J., Bodsworth, N. J., Atkinson, T. \& Minton, N. P. (1992b). The complete amino acid sequence of the Clostridium botulinum type E neurotoxin, derived by nucleotidesequence analysis of the encoding gene. European Journal of Biochemistry 204, 657-667.

Yokosawa, N., Tsuzuki, K., Syuto, B. \& Oguma, K. (1986). Activation of Clostridium botulinum type E toxin purified by two different procedures. Journal of General Microbiology 132, 19811988. 